\title{
O processo de produção de uma injustiça ambiental e seus impactos: o caso do CTR Rio em Seropédica
}

Producing an environmental injustice and its impacts: the case of CTR Rio in Seropédica

Le processus de production d'une injustice environnementale et ses impacts : le cas de CTR Rio à Seropédica

El proceso de producción de una injusticia ambiental y sus impactos: el caso del CTR Rio en Seropédica

\section{Tatiana Cotta G. Pereira}

\section{CpenEdition}

Journals

Edição electrónica

URL: http://journals.openedition.org/espacoeconomia/16546

DOI: 10.4000/espacoeconomia.16546

ISSN: 2317-7837

Editora

Núcleo de Pesquisa Espaço \& Economia

Refêrencia eletrónica

Tatiana Cotta G. Pereira, «O processo de produção de uma injustiça ambiental e seus impactos: 0 caso do CTR Rio em Seropédica », Espaço e Economia [Online], 19|2020, posto online no dia 01 setembro 2020, consultado o 09 setembro 2020. URL : http://journals.openedition.org/ espacoeconomia/16546; DOI : https://doi.org/10.4000/espacoeconomia.16546

Este documento foi criado de forma automática no dia 9 setembro 2020.

(C) NUPEE 


\section{O processo de produção de uma injustiça ambiental e seus impactos: o caso do CTR Rio em Seropédica}

Producing an environmental injustice and its impacts: the case of CTR Rio in Seropédica

Le processus de production d'une injustice environnementale et ses impacts : le cas de CTR Rio à Seropédica

El proceso de producción de una injusticia ambiental y sus impactos: el caso del CTR Rio en Seropédica

Tatiana Cotta G. Pereira

\section{Introdução}

1 O município de Seropédica, localizado a cerca de 70 quilômetros da cidade do Rio de Janeiro, pode ser considerado uma hiperperiferia ${ }^{1}$. Desmembrado do município de Itaguaí em 1995, tem seu desenvolvimento a partir de duas funções distintas: a existência da Universidade Federal Rural do Rio de Janeiro (UFRRJ) e de uma sede da Empresa Brasileira de Pesquisa em Agropecuária (EMBRAPA), e a extração de areia. No primeiro caso, a presença sobretudo da universidade o torna domicílio de estudantes, professores e técnicos. A cidade tem uma função de moradia universitária, que impulsiona, também, o setor terciário da economia. A outra função primordial é servir determinados recursos naturais (areia, pedra e brita) para as demais cidades da região metropolitana e de outras áreas do estado do Rio de Janeiro. Por essa função ela já se constituía como zona de sacrifício $^{2}$ antes mesmo da implementação do Centro de Tratamento de Resíduos Rio (CTR Rio), reforçada tanto pela presença da CTR quanto pela chegada, no ano de 2014, das milícias. Atualmente, ocorre também atração de empresas em função do Porto de Itaguaí. 
2 Nessa hiperperiferia é construída, em 2011, a CTR Rio, para receber o lixo de Seropédica, Itaguaí e do município do Rio de Janeiro. Impulsionada pela premente necessidade de fechamento do aterro controlado de Jardim Gramacho, cujo fechamento era previsto para o ano de $2004^{3}$. Pela então recente Política Nacional de Resíduos Sólidos (Lei 12.305/10), que prevê os aterros sanitários como forma ambientalmente adequada de disposição final de resíduos sólidos e estabelece o prazo de 4 (quatro) anos para o fechamento de todos os lixões no país. Tal demanda de fechamento do aterro de Jardim Gramacho, somada à realização de megaeventos - os Jogos Pan Americanos em 2007, a Copa de 2014 e os Jogos Olímpicos de 2016 - a cidade do Rio de Janeiro lança, em 2003, através da COMLURB, sua empresa municipal de limpeza urbana, um edital de licitação do tipo menor preço ${ }^{4}$. O objeto do edital era a "concessão dos serviços de implantação e operação do centro de tratamento de resíduos sólidos do município do Rio de Janeiro - CTR RIO". O projeto inicial previa a construção de um aterro sanitário e sete estações de transbordo, sendo duas a serem reformadas e cinco construídas, mais o transporte do lixo das estações para o aterro.

3 É a partir desse quadro complexo que o presente artigo pretende analisar a função do município de Seropédica na dinâmica metropolitana: o reforço de seu papel de zona de sacrifício no processo de metropolização em curso, que joga para as bordas metropolitanas os empreendimentos indesejáveis da metrópole, caracterizando uma relação de hierarquia entre as cidades $^{5}$, submetendo o município periférico a uma série de impactos, analisados aqui especialmente os socioambientais .

\section{Metropolização e suas Tessituras}

4 A ideia de metrópole estabelece, necessariamente, uma hierarquia, em que ocorre o predomínio de uma cidade sobre outras, em que a metrópole utiliza os espaços das outras para seu próprio desenvolvimento, atraindo trabalhadores, capital e formando redes que se conectam no tecido urbano. Contudo, nem a ocupação nem a circulação se faz de maneira equânime, tampouco a relação que a cidade central estabelece com as outras - periféricas. Essa relação acaba por gerar desigualdades espaciais, sociais, ambientais e econômicas entre elas.

Desta forma, historicamente é possível afirmar que a metrópole é uma grande cidade que coloniza, qualitativamente, outros territórios à sua volta, dependentes dessa cidade principal, que acaba se constituindo como uma centralidade no espaço da região metropolitana, designação recebida pelo conjunto de municípios que participam dessas relações e que formam uma conurbação. Lefebvre já coloca isso: “O espaço dominante, o dos centros de riqueza e de poder, se esforça para moldar os espaços dominados, os das periferias. Ele reduz a si, por uma ação frequentemente violenta, os obstáculos e resistências" (LEFEBVRE, 2006, p.48). E Rosa Robira aprofunda:

É qualificado como área ou região metropolitana aquele território mais ou menos urbanizado que fica em torno de uma grande cidade e depende dela. Avaliando-se qualitativamente, pode-se considerar que se trata de um território colonizado por uma grande cidade; esta explora seu ouro e sua prata, ou seja, seus recursos - água, solo, trabalho...-, impõe-lhe seu modo de organização e em troca recebe bijuterias, ou seja, aqueles equipamentos ou infraestruturas que a grande cidade expulsa: indústrias mais ou menos incômodas ou poluidoras, urbanização marginal ou secundária, aeroportos, rodovias, presídios, aterros sanitários, plantas de tratamento... (ROBIRA, 2012, p.13) 
Então, se temos, de um lado, um núcleo metropolitano que "explora o ouro", de outro temos as cidades periféricas como aquelas que são "exploradas" e recebem "bijuterias". Assim, o reverso da metrópole é a periferia. As periferias são, dentro do contexto metropolitano, os espaços da "sobra", onde não há interesse do capital imobiliário nem investimentos do setor público, numa relação dialética que tem como consequência óbvia a não valorização da terra e o local perfeito de moradia dos pobres.

7 Portanto, podemos destacar inicialmente a ideia de periferia a partir de dois eixos principais: primeiro como oposição ao centro, em olhar geográfico, em oposição à metrópole, à cidade central, aquela que atraiu o trabalhador. Um segundo eixo aponta para a periferia como espaço da moradia dos pobres, sem serviços urbanos e equipamentos básicos.

8 Essa realidade, contudo, vem mudando durante o século XXI, tendo como pano de fundo, conforme explicam Klink e Souza (2017), as mudanças no sistema de acumulação e no modo de regulação, passando a ocorrer uma circulação internacional de fluxos financeiros em escala relativamente inédita. 0 capitalismo financeiro, desterritorializado do chão da fábrica, investindo em tecnologia, traz consigo uma tendência à automatização total das fábricas e à produção de sistemas ciberfísicos, que combinam máquinas com processos digitais.

9 Além disso, a liberalização dos mercados de capitais e a criação de novas engenharias financeiras, como a securitização e a crescente influência dos agentes financeiros sobre o desenho da política macroeconômica de viés monetarista, constituíram um ambiente propício à circulação internacional de fluxos financeiros em escala relativamente inédita. Tal penetração das finanças no mundo industrial-fordista também transformou uma lógica até então pautada por estabilidade e previsibilidade. As finanças e a antecipação de fluxos de renda futura para o presente (a chamada capitalização) facilitaram a reestruturação da economia para um sistema mais flexível, analisado por David Harvey em termos da aceleração de tempo e espaço. A partir desse período, presenciamos a proliferação de projetos e estratégias empresariais marcados por retornos mais rápidos (período de repagamento de investimentos iniciais), obsolescência precoce de investimentos e ativos e ajustes espaciais intensos, envolvendo relocação de plantas industriais em escala global. (KLINK; SOUZA, 2017, p. 382)

10 Essa mudança, no campo da produção do espaço vem sendo colocada como um novo processo de metropolização, com características muito próprias, advindas da globalização. Mas, embora pareça que estamos integrados pelas redes de comunicação, por valores e modos de vida comuns, numa urbanização completa da sociedade, tal qual já apontado por Lefebvre (1999), há tempos, de fato, a desigualdade socioespacial permanece, embora com outras características. A metropolização em curso tende a reproduzir nos espaços sociais a lógica de acumulação do atual estágio do capitalismo, reproduzindo, inclusive suas desigualdades.

11 Destacaremos aqui como a questão ambiental entra nesse processo, trazendo o que Martinez-Alier (2009, p. 34) chama de "deslocamento geográfico das fontes dos recursos e das áreas de descarte dos resíduos", em que os países desenvolvidos "exportam" empresas poluidoras, tecnologias obsoletas, resíduos perigosos ou inúteis, e "importam" recursos naturais e conhecimentos tradicionais, apropriando-se deles. 
Desta forma, os problemas ambientais, embora possam ser vistos e sentidos em qualquer parte do mundo, ganham uma dimensão de análise a partir da desigualdade espacial, cujo referencial teórico é o movimento por Justiça Ambiental:

O que faz com que se possibilite distribuir os riscos ambientais para os trabalhadores e os pobres é a segregação de classe das localizações residenciais. Somente através da segregação da classe trabalhadora e dos pobres em áreas residenciais específicas, longe dos ricos, é que os proprietários, gerentes e investidores podem direcionar a contaminação ambiental para os estratos socioeconômicos mais baixos e longe de si próprios. (GOULD, 2004, p. 71)

13 Assim, ocorrem os conflitos ecológicos distributivos, em que "alguns grupos da geração atual são privados do acesso aos recursos e serviços ambientais, e sofrem muito mais com a contaminação" (MARTINEZ-ALIER, 2009, p.36), trazendo a dimensão ambiental para o contexto das desigualdades no capitalismo, demonstrando que ocorre um desequilíbrio na distribuição dos benefícios e malefícios ambientais, cujo exemplo clássico é justamente o caso de alocação de aterros sanitários.

Portanto, o rearranjo produtivo do capital tem imposto às cidades "reconfigurações", "renovações" e "requalificações" urbanas que esticam o tecido urbano, alargando suas fronteiras, inserindo novos municípios e cidades na rede metropolitana, estabelecendo novas centralidades, novas funções (urbanas) para localidades periurbanas e rurais, enfim, uma nova espacialização a partir desse rearranjo.

\section{A Construção do Aterro: Gerando Conflitos, Produzindo Consensos}

15 Antes de iniciar nossa narrativa, vamos apresentar brevemente alguns dados sobre os dois municípios aqui colocados, a fim de compreender melhor a desigualdade real entre eles, o que demonstra, na nossa compreensão, a injustiça ambiental orquestrada, uma vez que tal desigualdade acabou por impor um empreendimento indesejável de um município em outro, reforçando seu papel de zona de sacrifício.

Tabela 1: Dados comparativos entre a cidade polo e a cidade periférica

\begin{tabular}{|c|c|c|}
\hline & $\begin{array}{c}\text { Rio de Janeiro } \\
\text { (metrópole) }\end{array}$ & $\begin{array}{c}\text { Seropédica } \\
\text { (hiperperiferia) }\end{array}$ \\
\hline $\begin{array}{c}\text { População estimada } \\
(2019)\end{array}$ & $\begin{array}{c}6.718 .903 \text { pessoas }(52 \\
\% \text { da pop. da RMRJ) }\end{array}$ & $\begin{array}{c}82.312 \text { pessoas } \\
(0,7 \% \text { da pop. da } \\
\text { RMRJ) }\end{array}$ \\
\hline $\begin{array}{c}\text { Participação da população } \\
\text { no total de eleitores do estado } \\
(2018)\end{array}$ & $39 \%$ & $0,4 \%$ \\
\hline $\begin{array}{c}\text { Escolaridade da população } \\
(2015)\end{array}$ & $\begin{array}{c}95,8 \% \text { alfabetizados; } \\
24,7 \% \text { com graduação ou } \\
\text { mais }\end{array}$ & $\begin{array}{c}93 \% \text { alfabetizados; } \\
8,4 \% \text { com graduação ou } \\
\text { mais }\end{array}$ \\
\hline PIB total (2019) & $\mathrm{R} \$ 472.774 .485$ & $\mathrm{R} \$ 1.894 .661$ \\
\hline PIB per capita (2019) & $\mathrm{R} \$ 57.462$ & $\mathrm{R} \$ 23.080$ \\
\hline IDHM (2010) & 0,799 & 0,713 \\
\hline Trabalho informal (2015) & $20,68 \%$ & $35,47 \%$ \\
\hline
\end{tabular}

Fontes: IBGE, TRE-RJ e Atlas das Condições de Vida da RMRJ (PUC-Rio) 
17 O caso da vinda de todo o lixo gerado na cidade do Rio de Janeiro (cerca de 9500 toneladas por dia) para o município de Seropédica foi muito noticiado à época, tanto por conta da nova Política Nacional de Resíduos Sólidos (Lei 12305/10) como em função da grande resistência que os seropedicenses colocaram no processo. A ideia difundida era a de que o Rio de Janeiro daria uma disposição final ambientalmente adequada aos seus resíduos sólidos urbanos, sendo exemplo para o país de práticas ambientais sustentáveis. Contudo, o caminho não foi fácil.

Como dito na introdução, o lixo do município do Rio de Janeiro era primordialmente despejado no aterro controlado de Jardim Gramacho, no município de Duque de Caxias, recebendo cerca de $65 \%$ do que era diariamente coletado. Até 1995, Jardim Gramacho recebia, além do lixo urbano, lixo químico, hospitalar e industrial das cerca de 200 fábricas que compõem o polo industrial da Baixada Fluminense. A partir daí, passa a ser um aterro controlado, recebendo apenas resíduos sólidos urbanos e da construção civil. Em 1997 recebe o diagnóstico de necessidade de fechamento até março de 2004, sob risco de rachadura do solo e consequente contaminação da Baía de Guanabara.

Portanto, o maior depósito de lixo da região precisava ser fechado, o que efetivamente ocorreu apenas em 03 de junho de 2012. Segundo exposto no Decreto 27397/06, item 2.18, o plano era "a desativação gradual destas duas unidades ${ }^{6}$ a partir de janeiro de 2005, início de operação da CTR Rio, quando o lixo do Município do Rio passaria a ser disposto na nova instalação licenciada." Essa nova unidade seria indicada a partir da empresa vencedora da licitação lançada pela COMLURB em 2003, que previa

A decisão de licitar a implantação e operação de um novo aterro sanitário para a disposição final dos resíduos sólidos urbanos coletados no Município do Rio de Janeiro foi o resultado de amplas discussões e análises técnicas desenvolvidas pelos integrantes da Equipe Macro-Funcional Terra, criada pelo Decreto Municipal no 19.826, de 27/04/2001, composta por técnicos da COMLURB e das Secretarias Municipais de Meio Ambiente - SMAC, de Urbanismo - SMU, de Governo - SMG, representando as Subprefeituras, de Obras e Serviços Públicos - SMO e de Saúde SMS. (item 1.1 do Decreto 27397/06)

Note-se que a licitação é uma decisão de órgãos do município do Rio de Janeiro, entretanto, o resultado da licitação, segundo o relato contido no Decreto 27397/06, previa a possibilidade de que o CTR fosse construído fora do âmbito municipal:

As empresas Marquise, Júlio Simões, Caenge e Galvão, apresentaram terrenos para implantação do CTR Rio situados dentro do Município do Rio de Janeiro, todos localizados na região de Paciência. A empresa Bom Tempo apresentou um terreno no Município de Magé e a empresa S.A.Paulista ofertou uma área no Município de Itaguaí.

21 Outro ponto que vale destaque é o da localização ambiental do empreendimento: o próprio edital de licitação pedia que a empresa candidata indicasse a área, “(...) desonerando o Município dos dispendiosos estudos para identificação e avaliação ambiental preliminar das áreas disponíveis." (Item 1.3 do Decreto 27397/06.) Ou seja, as áreas para a construção do empreendimento eram indicadas pelas concorrentes sem nenhum tipo de estudo prévio de viabilidade ambiental, que é uma obrigação constitucional.

22 Assim, a empresa vencedora foi a Júlio Simões Logística S/A, que indicou como área a Fazenda Santa Rosa, no bairro de Paciência, zona oeste da cidade do Rio de Janeiro. Esse resultado foi questionado no Judiciário pelas concorrentes, mas foi homologado em 
19/08/20037 , e o contrato no 318/2003 com a empresa - Concessão dos Serviços de Implantação e Operação do Centro de Tratamento de Resíduos Sólidos Urbanos do Município do Rio de Janeiro - CTR Rio foi assinado em 21/08/2003.

Diversos fatos, contudo, acabaram por impedir a construção do aterro na área: i) a organização da população local em torno do Fórum de Meio Ambiente e Qualidade de Vida da Zona Oeste e da Baía de Sepetiba, contando com o apoio de vereadores do PSDB, como Lucinha e Luiz Paulo Corrêa, que organizaram audiências públicas na Câmara de Vereadores para avaliar o empreendimento e a localização, demonstrando como a zona oeste do Rio de Janeiro recebe as cargas negativas da cidade; ii) a fazenda indicada era cercada de favelas e loteamentos por todos os lados, ou seja, havia pessoas no entorno do empreendimento; iii) o contrato assinado foi objeto de denúncias no Tribunal de Contas do Município do Rio de Janeiro, que emitiu parecer opinando pela sustação do mesmo ${ }^{8}$; iv) diversos processos judiciais e administrativos que questionavam a criação de uma Área de Especial Interesse Funcional - AEIF no Plano Diretor do Rio de Janeiro por Decreto e não por lei; v) existência de diversos pareceres que indicavam que o local ficava muito próximo à Base Área de Santa Cruz e do Aeroporto de Jacarepaguá, estando inserido em Área de Segurança Aeroportuária (ASA), não podendo haver nada que atraia "pássaros"; vi) era também época de uma acirrada disputa pela prefeitura municipal e os dois candidatos se comprometeram publicamente a não levar o aterro para o bairro.

$\mathrm{O}$ aterro, nesse caso, seria construído em área dentro do próprio município, o que seria ideal tanto em termos de observância do pacto federativo - que pressupõe igualdade jurídica entre os municípios - quanto da justiça ambiental, pois o lixo gerado no território do município é responsabilidade do próprio, que é também o que dispõe o art. 10 da PNRS. Mas, por toda essa resistência, pelos empecilhos não só legais como políticos, e para aproveitar a licitação realizada, uma área no município de Seropédica foi escolhida.

O primeiro grande arranjo para a implementação da CTR em Seropédica foi feito no resultado da licitação da COMLURB. Com a impossibilidade política e jurídica da CTR em Paciência e considerando (1) a situação de esgotamento de Jardim Gramacho e Gericinó, (2) que o projeto da CTR já havia sido aprovado ambientalmente pela FEEMA (atual INEA), e (3) que não havia na região metropolitana do Estado do Rio de Janeiro aterros sanitários licenciados e com capacidade de receber a quantidade de lixo gerado no Município do Rio, a Comissão coordenada pela COMLURB julgou "que a manutenção do contrato $n^{2} 318 / 2003$, firmado para implantação e operação da CTR Rio é a alternativa mais rápida e segura para solucionar o problema do sistema de Destinação Final do Município do Rio de Janeiro." (item 1.8 do Decreto 27397/06).

A diretora da empresa S/A Paulista, Adriana Felipetto, explicou, em um evento na Fundação Getúlio Vargas ${ }^{9}$ que a Júlio Simões, empresa vencedora da licitação e que tinha assinado contrato com o município do Rio, havia comprado a S/A Paulista, empresa que tinha ficado em terceiro lugar na licitação. Essa empresa era dona de uma grande área em Seropédica, e a havia indicado na licitação para a construção da CTR. Além disso, a S/A Paulista detinha o conhecimento da tecnologia, uma vez que tinha construído o aterro sanitário de Nova Iguaçu. S/A Paulista e Júlio Simões se unem então para aproveitar o contrato feito por uma (Júlio Simões) na área da outra (S/A Paulista), formando a empresa SERB, atual CICLUS, específica para a construção e gestão do aterro de Seropédica. Tudo isso com o apoio institucional da Prefeitura do Rio de 
Janeiro, a partir do parecer da Comissão, conforme Decreto 27397/06 e Termo Aditivo n²003/318-01, celebrado entre a COMLURB e SERB.

O ex-vereador de Seropédica Mauro Britto ${ }^{10}$, afirmou que a compra do terreno pela S/A Paulista já foi com a intenção de fazer ali um aterro sanitário, porém ainda não estava claro como isso aconteceria ${ }^{11}$. Nessa época $(2002,2003)$, segundo Mauro Britto, vigorava a ideia de que a CTR atendesse ao consórcio de três municípios: Seropédica, Itaguaí e Mangaratiba, pois a possibilidade de Paciência não estava completamente descartada. Ele narra que, em seu segundo mandato (2005/08) surgiu o interesse do município do Rio de Janeiro de participar do consórcio, embora ainda não com a integralidade de seus resíduos urbanos:

Começou a haver um interesse da cidade do Rio de Janeiro, em virtude de Copa do Mundo, Olimpíadas, não sei o quê, do Ministério Público pressionar para terminar com Gramacho e os outros lixões do Rio de Janeiro. Parte do Rio de Janeiro fazia parte desse consórcio. Não faria parte Mangaratiba, faria parte Itaguaí, Seropédica e a Zona Oeste todinha da cidade do Rio de Janeiro, Jacarepaguá, Barra, Recreio, Santa Cruz. (BRITTO, entrevista).

A implementação da CTR-Rio em Seropédica também causou muita controvérsia e contou com diversas pessoas e grupos transitando entre as duas posições: a favor da sua implementação e contra.

Como pessoas e grupos a favor podemos destacar, conforme o relato de Britto, a própria presidência da república, ${ }^{12}$ o governador do estado, Sérgio Cabral, o prefeito do município do Rio de Janeiro, Eduardo Paes, os donos das empresas Júlio Simões e S/A Paulista, que uma vez construído o aterro fundiram-se como CICLUS para administrálo. No município de Seropédica, o prefeito Darci dos Anjos, que propôs os projetos de lei que viabilizaram a vinda da CTR, e sete vereadores dos dez da Câmara Municipal na legislatura 2005/2008.

Além dessas pessoas políticas, a população do bairro Mutirão, onde ficava o lixão de Seropédica, parecia a favor da CTR, embora não se manifestasse em nenhum local. Mas em uma entrevista com um casal, realizada em julho de 2011, eles garantiram que "a retirada do lixão foi muito boa" e que "a cidade está mais limpa". Outra moradora do local foi pelo mesmo caminho: "é melhor do que lixo a céu aberto". ${ }^{13}$

O grupo contra o empreendimento se constituiu como Fórum de Mobilização contra o Aterro de Seropédica. O Fórum foi formado em 2008 a partir de algumas lideranças locais: a então vereadora Maria José Salles Ferreira, presidente da Comissão de Meio Ambiente da Câmara; a engenheira agrônoma Rosangela Straliotto, pesquisadora da EMBRAPA e presidente do Conselho da Cidade de Seropédica; e diversos professores da Universidade Federal Rural do Rio de Janeiro, das áreas de geologia, engenharia florestal, economia e direito. A ADUR, sindicato dos docentes da UFRRJ, o SINTUR, sindicato dos técnicos da UFRRJ e o DCE da UFRRJ; a ACIAPS (Associação Comercial, Industrial e Agropastoril de Seropédica), a AMAC (Associação de Moradores da Agrovila Chaperó), a FRAMES (Federação de associações de Moradores de Seropédica), a ONG Quinto Elemento, entre outros, também compunham o Fórum. Vale ainda destacar que a partir da perda do mandato de Darci dos Anjos (2010), o novo prefeito, Arthur Martinazzo, se posiciona contra a instalação do aterro e além de tomar providências administrativas e judiciais, passa a participar das reuniões através de seu secretário de meio ambiente, Ademar Quintella.

Cabe aqui explicitarmos os motivos da instauração desse conflito socioambiental. 

inaugura o CTR Rio, com a ausência do então prefeito de Seropédica, Arthur Martinazzo, contrário à instalação do empreendimento e impedido judicialmente de tentar reverter a situação. Para a população seropedicense, o sentimento de derrota era total, entendendo que se tratava de uma luta "de Davi contra Golias". A compreensão do pouco peso político do município no jogo eleitoral estadual, a certeza de que teria havido propina para o prefeito que concedeu a licença e a noção de racismo/injustiça ambiental foram aparecendo como as grandes conclusões de todo o episódio. Infelizmente Seropédica se tornaria "o lixão do Rio de Janeiro". 


\section{Impactos Ambientais Previstos e Sentidos: o CTR Rio hoje}

Embora haja diversas formas de encarar o problema aqui colocado, temos clareza de que estamos narrando-o sob uma ótica bastante específica: a da população de uma hiperperiferia. Essa população tem direitos assegurados: vida, igualdade material, dignidade e meio ambiente ecologicamente equilibrado. É sob a ótica desses direitos que percebemos a produção da injustiça ambiental produzida. No entanto, não ignoramos que a tecnologia de aterro sanitário é melhor que um lixão, assim como sabemos ser possível gerar energia através do lixo. Mas nos ateremos aqui à dimensão socioambiental.

Os Estudos de Impacto Ambiental estão previstos no art.225, §1², IV da Constituição Federal de1988. A exigência constitucional é para que se façam tais estudos previamente à "instalação de obra ou atividade potencialmente causadora de significativa degradação do meio ambiente, estudo de impacto ambiental, a que se dará publicidade". É a Resolução CONAMA no001/86 que regulamenta a matéria, estabelecendo o conceito jurídico de impacto ambiental, conforme preceitua o art.1ํ:

(...) considera-se impacto ambiental qualquer alteração das propriedades físicas, químicas e biológicas do meio ambiente, causada por qualquer forma de matéria ou energia resultante das atividades humanas que, direta ou indiretamente, afetam:

I - a saúde, a segurança e o bem-estar da população;

II - as atividades sociais e econômicas;

III - a biota;

IV - a qualidade dos recursos ambientais.

41 O impacto a ser avaliado pode ocorrer nos meios físico, biótico ou socioeconômico. Como coloca Edésio Fernandes (2004) o impacto é socioambiental, expressão utilizada, segundo esse autor, a partir da década de 1980, sendo mais precisa justamente porque compreende o meio ambiente não apenas como a natureza em si, mas como o todo integrado. $\mathrm{O}$ autor também estabelece impacto como processo, algo que acontece continuamente no meio ambiente, se relacionando inclusive com a produção de (in)justiças ambientais. Portanto, os impactos socioambientais não devem ser reduzidos a uma dimensão meramente técnica, mas devem ser vistos como acontecimentos gerados pela ação humana que atuam e modificam o cotidiano social.

Além disso, os impactos não são classificados a priori como ruins, haja vista serem uma modificação do meio por conta do desenvolvimento de atividades humanas, havendo impactos positivos e negativos, o que nos leva a perceber que a noção de impacto "inclui um julgamento do valor da significância de um efeito" (MUNN, 1979, p.43, tradução livre). Assim, o impacto ambiental, juridicamente falando, é o resultado de qualquer ação humana em seu meio e defini-lo como positivo ou negativo consiste num juízo de valor.

43 A maneira mais fácil de relacionar os impactos ambientais previstos pelo CTR Rio são aqueles definidos pelo EIA/RIMA ${ }^{16}$ elaborado: 
Tabela 2 : Impactos ambientais gerados pelo empreendimento

\begin{tabular}{|l|l|l|l|}
\hline IMPACTOS & TOTAL & POSITIVOS & NEGATIVOS \\
\hline IMPLANTAÇÃO & 21 & 06 & 15 \\
\hline OPERAÇÃO & 24 & 08 & 16 \\
\hline ENCERRAMENTO & 04 & 01 & 03 \\
\hline TOTAL & 49 & 15 & 34 \\
\hline
\end{tabular}

Fonte: Quadro 9-1 do RIMA elaborado pela Empresa Vereda Estudos e Execução de Projetos Ltda.

Dentre os impactos ambientais negativos previstos na fase de implantação e funcionamento, vale destacar: i) geração de emissão atmosférica e material particulado; ii) indução a riscos de deslizamento e de erosão; iii) variação do valor das terras e imóveis residenciais; iv) incômodos à vizinhança; v) deterioração do sistema viário existente; vi) riscos de enchente e de assoreamento nos corpos d'água; vii) risco de contaminação do lençol freático e das águas superficiais.

Foram previstos como impactos positivos nas mesmas fases: i) variação de tributos; ii) variação da Oferta de Empregos; iii) fomento da dinâmica econômica; iv) indução ao bem-estar da comunidade da Área de Influência Indireta; v) interferência na saúde da população local; vi) recuperação do biogás

Observando essas previsões dentro de um quadro institucional, já é possível vislumbrar que os grandes atingidos pelos impactos negativos seriam os moradores de Seropédica, especialmente os da Agrovila Chaperó, comunidade do entorno imediato, como demonstra esse mapa produzido por Tatiana Freitas Valle ${ }^{17}$ :

\section{Mapa 1: Localização de moradores de Chaperó no entorno do CTR-Rio}

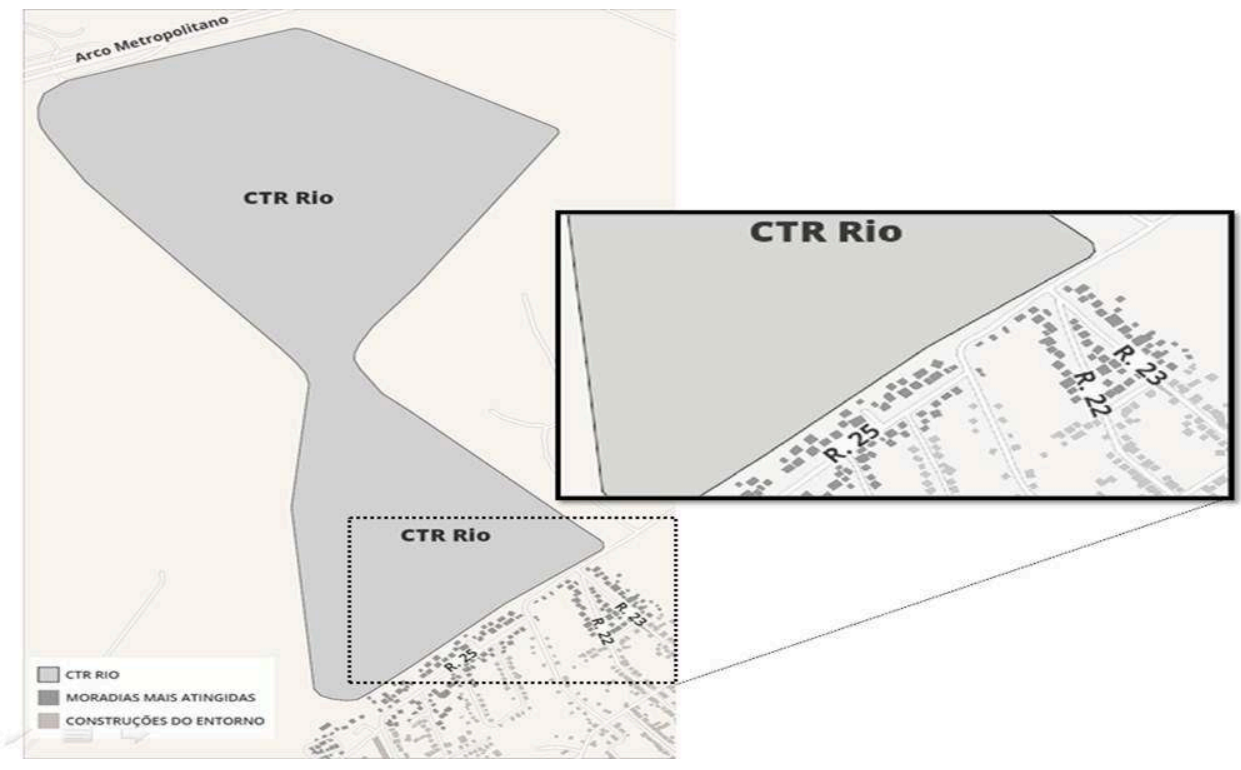

Fonte : Imagem cedida por Tatiana Freitas Vale.

Durante cinco anos (2010/2015) tive a oportunidade de andar pelo bairro de Chaperó para avaliar in loco as modificações na paisagem e, ainda, entrevistar moradores. Em termos de impactos ambientais sentidos por eles, podemos apontar, sobretudo, o forte 
odor desagradável, a presença maciça de moscas e urubus, a modificação da paisagem e a desvalorização completa da terra.

Essas percepções permanecem, bastando passar pelo Arco Metropolitano na altura do CTR de janelas abertas (rodovia Raphael de Almeida Magalhães Km 107). Em entrevista à Flavia Coutinho Guilherme, que foi subsecretária na secretaria de ambiente e agronegócio de Seropédica entre julho de 2018 e janeiro de 2020, perguntada sobre os impactos negativos do CTR-Rio ela aponta:

- Ausência de comunicação e transparência com os órgãos ambientais locais, principalmente dos municípios de Seropédica e Itaguaí;

- Ausência de manutenção e também de serviços de rotina adequados, fazendo com que odores desagradáveis tenham alcance regional;

- Programas falhos, principalmente de controle de animais (principalmente aves);

- Aumento de vetores nas comunidades próximas (principalmente moscas) e assoreamento de canais, causando inundações e perdas econômicas (GUILHERME, F. entrevista)

Vale destacar que Tatiana Freitas Valle, ao analisar os impactos ambientais do funcionamento das 5 Estações de Tratamento de Resíduos (ETRs) funcionando atualmente no município do Rio de Janeiro ${ }^{18}$, relata os mesmos impactos, especialmente o odor desagradável e a presença de moscas e urubus.

Duas questões técnicas merecem destaque: o chorume e os flares.

Em janeiro de 2012 entrevistamos o motorista de um caminhão que transportava o chorume produzido até a Companhia Águas de Niterói, do outro lado da Região Metropolitana, já que ainda não havia tratamento para o mesmo no local. Segundo ele eram produzidos cerca de dezoito mil litros de chorume por hora, enchendo de seis a oito caminhões por dia. Essa situação fez com que a empresa fosse multada duas vezes pelo INEA (em agosto de 2012 e fevereiro de 2013) e uma vez pela COMLURB (fevereiro de 2013). A situação ficou crítica, havendo protesto em Niterói, Audiência Pública, sendo feito então um acordo entre a Secretaria Estadual do Ambiente e a CICLUS, com novo prazo para cumprir tal obrigação, até maio de 2014. Esse prazo, contudo, não foi cumprido, como noticia órgão de imprensa seropedicense em agosto de 2014:

«Chorume da CTR continua sendo levado para Niterói contrariando matéria veiculada no Jornal o Globo com o título "Aterro de Seropédica passa a descontaminar o material poluente ». O Secretário de Ambiente e Agronegócios de Seropédica Ademar Quintela disse: “A notícia que saiu no Jornal o Globo não é verdadeira, porque a estação de tratamento de chorume da CICLUS que se encontra no Município de Seropédica não está operando ainda, ela teve dois testes pontuais que foram feitos para ver se existia possibilidade de sair tratado esse chorume.

Só que a CTR não tem ainda o emissário construído até o ponto de onde será jogado o chorume tratado, e nem está autorizado a jogar este material no Rio Piloto, então não existe esta possibilidade de que o chorume após tratado ser jogado no Município de Seropédica. Hoje o que existe é que este chorume está sendo levado para Estação de Icaraí, Niterói onde está tendo um tratamento primário e sendo jogado na Baia de Guanabara. (CALDERINI, L. 2014)

Em fevereiro de 2016 ocorre vazamento de chorume, noticiado no site do G1:

A prefeitura de Seropédica, na Baixada Fluminense, notificou nesta segunda-feira (22) a empresa responsável pela Central de Tratamento de Resíduos instalada na cidade. Após a chuva do domingo (21) houve vazamento de chorume, líquido que sai do lixo, para um córrego e para o reservatório subterrâneo de água. Como mostrou o RJTV, o Aquífero Piranema pode ter sido contaminado com o vazamento. 
O reservatório de água tem capacidade para abastecer a população do Rio durante um mês se for necessário. Ele fica localizado a 180 metros de profundidade, entre o oeste do Rio e os municípios de Queimados, Japeri, Seropédica e Itaguaí.

Além do chorume que vazou, o córrego também recebe o esgoto das casas do bairro de Aperó. Os moradores disseram que a contaminação trouxe prejuízos para eles. Eles denunciam que esta não é a primeira vez que ocorre esse tipo de acidente. Os relatos são de que a água ficou escura, brilhante e com cheiro forte.

Não bastasse esse episódio, em maio de 2019 o Tribunal de Contas do Município do Rio de Janeiro divulgou o seguinte relatório:

Um relatório do Tribunal de Contas do Município do Rio (TCM) alerta para o risco de vazamento de chorume no aterro sanitário de Seropédica, na Região Metropolitana. A constatação foi feita no curso da auditoria de conformidade na Comlurb, a empresa de limpeza urbana da cidade, que aconteceu entre os dias 11 de março e 9 de abril.

Segundo os conselheiros, o vazamento de chorume pode provocar a contaminação do lençol freático. Na avaliação do TCM, a empresa Ciclus Ambiental - que opera o aterro sanitário - "não tem tido, nos últimos anos, capacidade de tratar internamente todo o chorume gerado no aterro sanitário".

A empresa construiu lagoas para o armazenamento do chorume não tratado e enviar parte desse chorume para tratamento externo. Mesmo com tratamento, o volume de chorume vem aumentando significativamente. No final de março, atingiu $264 \mathrm{mil}$ metros cúbicos, o que corresponde a $80 \%$ da capacidade total de armazenamento.

Segundo o relatório do TCM, se nada for feito em breve podem ocorrer paralisações do tratamento interno e do envio para tratamento externo. E neste cenário, um acidente ambiental ocorreria em 44 dias, com o lançamento de mais de dois milhões de litros de chorume por dia nas vizinhanças do aterro. (SANTOS, A. P.; MARIA, E. 2019)

1 Flavia Coutinho Guilherme nos informa que a Secretaria de Ambiente e Agronegócio de Seropédica multou a CICLUS, em sua gestão (2018/20), com relação ao chorume, especificamente, solicitando envio mensal do

(...) detalhamento da quantidade de chorume tratado na central, apresentando a análise do efluente na entrada e saída do tratamento, para os parâmetros definidos em licença ambiental; Cópia do último Certificado de Calibração das balanças, emitido pelo INMETRO; ..." Tais informações vinham sendo prestadas ao município de Seropédica mensalmente e a partir do mês 08/2019 não é apresentada mais a resposta a notificação № 079/2018. Valor da multa: R\$ 4.533,36. (GUILHERME, F. entrevista)

62 A outra questão são os flares, exigidos pelo INEA a partir de 2016, para queima do biogás produzido. Em 2018, embora tivessem sido instalados, não funcionavam efetivamente, gerando uma vultosa multa da Prefeitura de Seropédica "por operar aterro sanitário sem a devida captura/queima/tratamento de todo o gás gerado, verificada pela ausência de flare nos PDR's/PDG, ausência de fogo, emissão de gases poluentes para a atmosfera, forte odor ocasionando incômodos." (GUILHERME, F. entrevista).

63 É importante ressaltar que a empresa atua no seu entorno, o que se dá por conta do cumprimento das medidas condicionantes do processo de licenciamento. Assim, ocorreu o fechamento do lixão de Seropédica, cujas obras de engenharia foram finalizadas, conforme o projeto executivo aprovado pelo INEA. A empresa também 
implementou um Comitê de Responsabilidade Socioambiental, criou um Centro de Educação Ambiental e ainda o PISCA - Plano de Inclusão dos Catadores, com a intenção de auxiliar os ex-catadores dos lixões de Seropédica e Itaguaí no mercado formal, auxiliando na criação da COOTRASER (Cooperativa de Catadores de Seropédica), gerando, assim, 34 postos de trabalho, além de acompanhamento social e incentivo à escolaridade dos mesmos. Por esse último projeto, a empresa foi vencedora do Prêmio de infraestrutura de Sustentabilidade do setor privado do Banco Interamericano de Desenvolvimento (BID) na categoria Pessoas e Liderança, que premia o projeto que apresenta a maior extensão dos impactos positivos na qualidade de vida das pessoas e da comunidade onde está localizado.

Ainda no âmbito de cumprimento de medidas condicionantes, a empresa urbanizou uma praça em Seropédica, fez o plano de manejo da APA Catumbi e um projeto de biblioteca pública, ainda não executado. Também é importante ressaltar que o Rio vem sendo apontado como a capital com melhor índice de sustentabilidade da limpeza urbana, conforme notícia do ano passado:

O Rio de Janeiro é exemplo nacional na gestão do lixo urbano. O município recebeu importante reconhecimento com a divulgação do Índice de Sustentabilidade da Limpeza Urbana (ISLU) 2019: a cidade foi considerada a melhor capital brasileira na gestão do lixo. (...)

O Rio de Janeiro foi a primeira cidade a atender à Política Nacional de Resíduos Sólidos (PNRS), com o fechamento do Aterro de Gramacho e a inauguração do Centro de Tratamento de Resíduos CTR-Rio, em Seropédica. Esta unidade reúne tecnologia de ponta, inédita em toda a América Latina. São recolhidas diariamente, em todo o município, 10 mil toneladas de resíduos sólidos - incluídos nessa conta lixo domiciliar, público, RCC (resíduos de construção civil), grandes geradores e remoção gratuita.

Por fim, vale trazer a quantidade de resíduos recebida diariamente no CTR Rio, que foi modificada em 2016 através de um documento de averbação do INEA: a capacidade de 8000 toneladas/diárias para resíduos sólidos urbanos mais 1000 toneladas/diárias para resíduos sólidos industriais não perigosos (classe II) mudam para 10.400 toneladas/ diárias, sem discriminação do tipo de resíduo. É possível perceber também a ampliação do número de municípios depositários em relação ao inicialmente previsto:

Tabela 3: Resíduos sólidos urbanos diários por município no CTR Rio

\begin{tabular}{|l|l|}
\hline Município & RSU depositados (ton/dia) \\
\hline Mangaratiba & 23,7 \\
\hline Seropédica & 45,5 \\
\hline Itaguaí & 66,1 \\
\hline Magé & 141,6 \\
\hline Rio de Janeiro & 9565,2 \\
\hline TOTAL & 9.842 \\
\hline
\end{tabular}

Fonte: CUNHA, 2019.

Diante de todo o exposto, é possível perceber que vivemos como é possível para um país de terceiro mundo: aceitamos tecnologias obsoletas, promovemos conflitos e injustiças 
ambientais e ainda nos orgulhamos das nossas melhorias, utilizando índices que ignoram a dimensão humana em seu caráter integral, em que a qualidade de vida de todos deveria ser o parâmetro a ser observado.

Nesse sentido, a relação entre a metrópole do Rio de Janeiro e a hiperperiferia de Seropédica se estabelece como uma relação de colonização, em que os usos e funções do município são definidos por instâncias e atores de outros locais, reproduzindo no jogo político certa configuração espacial. Podemos afirmar que a forma e a função urbana de Seropédica foi redefinida a partir do interesse dos governos federal e estadual em erradicar os lixões existentes (interesse normatizado na lei e perseguido tanto pelo governador quanto pelo prefeito do município do Rio de Janeiro), associados à empresa S/A Paulista, proprietária da área e com conhecimento tecnológico para construir aterros sanitários (a tecnologia definida como ideal pela lei). O CTR Rio vai se concretizar como política pública de saneamento, cuja gestão é privada. A licitação que escolhe a área para esse uso é de outro município, o município central dentro da estrutura metropolitana a qual, até ali, Seropédica pouco participava de forma integrada. Ocorre, assim, a "construção especulativa do lugar" (HARVEY, 2005, p.174) no processo de metropolização do Rio de Janeiro, fragmentando o tecido urbano ainda mais e reforçando desigualdades. Reproduzimos, assim, a lógica de desigualdade espacial que o capitalismo produz.

\section{BIBLIOGRAFIA}

BRITTO, M.: entrevista [dez.2014]. Entrevistadora: Tatiana Cotta G. Pereira. Seropédica: UFRRJ, 2014.

BULLARD, R.D. Dumping in Dixie: Race, Class and Environmental Quality. $3^{\text {rd }}$. ed. Boulder, Colorado: Westview Press, 2000.

BULLARD, R.D. Enfrentando o racismo Ambiental no Século XXI. In: ACSELRAD, H.; HERCULANO, S.; PÁDUA, J.A. Justiça Ambiental e Cidadania. Rio de Janeiro: Relume Dumará: Fundação Ford, 2004.

CALDERINI, L. Esclarecimento sobre o chorume da CTR de Seropédica. Seropédica online [blog]. Seropédica, 6 agosto 2014. Disponível em: http://www.seropedicaonline.com/?p=23506\#. Acesso em 30 jul 20.

COMITÊ GUANDU. Resolução Comitê Guandu no38 de 28 de setembro de 2009. Disponível em:< http://www.ceivap.org.br/guandu/Res38.pdf>. Acesso em 11 abril 15.

CHORUME VAZA EM SEROPÉDICA APÓS FALTA DE LUZ, DIZ EMPRESA. O GLOBO [online]. 22 fevereiro 2016. Disponível em: http://g1.globo.com/rio-de-janeiro/noticia/2016/02/chorumevaza-em-seropedica-apos-falta-de-luz-diz-empresa.html. Acesso em 30 jul 20.

CUNHA, C.E.S.C.P. Proposta de Índice de Sustentabilidade Operacional de Aterros Sanitários (ISOAS). 2019. 268 f. Tese (Doutorado em Engenharia Sanitária e Ambiental). Universidade do Estado do Rio de Janeiro: Rio de Janeiro, 2019. 
FERNANDES, E. Impacto Socioambiental em Áreas Urbanas sob a perspectiva jurídica. Em: MENDONÇA, G. (org). Impactos Socioambientais Urbanos. Curitiba, PR: editora UFPR, 2004.

GOULD, K. A. Classe Social, Justiça Ambiental e Conflito Político. Em: ACSELRAD, H.; HERCULANO, S.; PÁDUA, J.A. Justiça Ambiental e Cidadania. Rio de Janeiro: Relume Dumará: Fundação Ford, 2004.

GUILHERME, F. C. entrevista [jul.2020]. Entrevistadora: Tatiana Cotta G. Pereira. Via gmail, 2020.

HARVEY, D. A produção capitalista do espaço. Tradução de Carlos Szlak. São Paulo: Annablume, 2005.

INSTITUTO BRASILEIRO DE GEOGRAFIA E ESTATÍSTICA (IBGE). Disponível em: https:// cidades.ibge.gov.br/. Acesso em 29 jul 20

JACOB, C. R. et all. Atlas das condições de vida na região metropolitana do Rio de Janeiro [recurso eletrônico] Rio de Janeiro : Ed. PUC-Rio , 2014

KLINK, J.; SOUZA, M. B. Financeirização: conceitos, experiências e a relevância para o campo do planejamento urbano brasileiro. Cadernos Metrópole, vol.19, no.39 São Paulo maio/ago. 2017

LEFEBVRE, H. A produção do espaço. Trad. Doralice Barros Pereira e Sérgio Martins (do original: La production de l'espace. 4 éd. Paris: ÉditionsAnthropos, 2000). Primeira versão : início - fev.2006

LEFEBVRE, H. A Revolução Urbana. Belo Horizonte: Ed. UFMG, 1999.

MARTINEZ-ALIER, J. O ecologismo dos pobres: conflitos ambientais e linguagens de valorização. Tradução de Maurício Waldman. São Paulo: Contexto, 2007.

MUNN, R.E. Environmental impact assessment. Toronto: John Wiley\&Sons, 1979.

PEREIRA, T. C. G.. Política Nacional de Resíduos Sólidos e um caso de injustiça ambiental como seu efeito socioespacial: a construção do aterro sanitário em Seropédica. In: XVII ENANPUR, 2017, São Paulo. Anais do XVII ENANPUR, 2017. v. ST4.

PREFEITURA DA CIDADE DO RIO DE JANEIRO. Rio de Janeiro se destaca na gestão do lixo e é melhor capital brasileira em Índice de Sustentabilidade Urbana. Disponível em: http:// www.prefeitura.rio/comlurb/rio-de-janeiro-se-destaca-na-gestao-do-lixo-e-e-melhor-capitalbrasileira-no-indice-de-sustentabilidade-urbana-2019/. Acesso em 31 jul 20.

QUAINO, L. Lixo do Rio em Seropédica divide opiniões. O GLOBO [online]. Rio de Janeiro, 16 abril 2012. Disponível em: http://g1.globo.com/rio-de-janeiro/rio-mais-limpo/noticia/2012/04/lixodo-rio-em-seropedica-divide-opinioes.html. Acesso em 27 mar 14.

ROBIRA, R. T. Áreas Metropolitanas: espaços colonizados. Em: CARLOS, A. F. A. e CARRERAS, C. (orgs). Urbanização e Mundialização: estudos sobre a metrópole. 2.ed. $1^{\text {a }}$ reimpressão. São Paulo: Contexto, 2012. pp.9-20.

SANTOS, A. P.; MARIA, E. Tribunal de Contas do Rio alerta para risco de vazamento de chorume no aterro de Seropédica, RJ. O GLOBO [online]. Rio de Janeiro, 3 maio 2019. Disponível em: https://g1.globo.com/rj/rio-de-janeiro/noticia/2019/05/03/tribunal-de-contas-do-rio-alertapara-risco-de-vazamento-de-chorume-no-aterro-sanitario-de-seropedica-rj.ghtml. Acesso em 30 jul 20.

TORRES, H. e MARQUES, E. "Reflexões sobre a hiperferiferia: novas e velhas faces da pobreza no entorno metropolitano". In: Revista Brasileira de Estudos Urbanos e Regionais, No 4, maio de 2001.

TRIBUNAL REGIONAL ELEITORAL DO RIO DE JANEIRO. Estatísticas do eleitorado. Ano 2018. Disponível em: https://www.tre-rj.jus.br/site/eleicoes/index.jsp? vmenu=quantitativo_eleitorado/busca_quantitativo.jsp. Acesso em 29 jul 20. 
VIÉGA, R. N. Desigualdade Ambiental e "Zonas de Sacrifício", 2006. Disponível em: www.livrosgratis.com.br/arquivos_livros/ea000392.pdf. Acesso em 15 maio 2012.

\section{NOTAS}

1. A hiperperiferia é um conceito trabalhado por Torres e Marques (2001) que procura indicar as cidades mais pobres entre as periféricas, as mais sujeitas a riscos e menos integradas ao tecido e às trocas urbanas.

2. Expressão "utilizada pelos movimentos de justiça ambiental para designar localidades em que se observa uma superposição de empreendimentos e instalações responsáveis por danos e riscos ambientais." (VIEGA, 2006, p.4).

3. Os estudos acerca da vida útil de Gramacho começam em 1997, quando "foram registrados escorregamentos nos maciços de lixo durante a operação regular do Aterro de Gramacho, o que indicou a necessidade de operá-lo de forma mais acurada." (item 2.5 do Decreto municipal 27397/06). O solo local apresentava uma série de rachaduras e as três equipes técnicas contratadas davam o mês de março de 2004 como prazo final para fechar o aterro e constituir uma nova área para o depósito final de resíduos sólidos urbanos do município do Rio.

4. O edital de concorrência pública $n^{\circ}$ 0003/2003, teve publicado seu aviso no Diário Oficial do Município do Rio de Janeiro em 13 de fevereiro de 2003. Essa publicação é apenas o "aviso de licitação", o conteúdo do edital deveria ser adquirido pelas partes interessadas em um endereço ali fornecido pelo valor de $\mathrm{R} \$ 200,00$. Desta forma, infelizmente, não conseguimos ter acesso ao conteúdo do mesmo.

5. Vale lembrar que não estamos falando aqui da celebração de um convênio ou consórcio entre municípios, mas do edital de um órgão municipal que vai jogar todo o seu lixo em outro município, a partir de alguns arranjos locais, nos moldes do "caminho da menor resistência" (BULLARD, 2000).

6. O aterro de Gericinó, que recebia menos quantidade de resíduos, encontrava-se também em situação crítica

7. Vale mencionar que, segundo o Decreto 27397/06, “o processo licitatório foi objeto de mais de 60 ações judiciais movidas por empresas e organizações não governamentais que tentaram de todas as formas obstaculizar o certame”. o próprio Ministério Público estadual abriu Inquérito Civil.

8. É a partir das recomendações do TCMRJ que o então prefeito Cesar Maia nomeia uma Comissão interdisciplinar, coordenada pela COMLURB, com o objetivo de "no prazo de até cento e vinte e dias, avaliar a experiência do atual processo licitatório e indicar os procedimentos a serem seguidos" (Decreto 26576/06). São as conclusões dessa Comissão que são publicadas no Decreto 27397/06, seis meses depois de nomeada e que constitui nossa principal fonte sobre o imbróglio que foi a questão da CTR em Paciência, na área indicada pela Júlio Simões, fazenda Santa Rosa.

9. Esse relato foi feito por Adriana Felipetto, então superintendente da S/A Paulista no evento "Café com Lei”, organizado e realizado pela Fundação Getúlio Vargas em 12 de novembro de 2010, sob o título "Licenciamento Ambiental do Aterro de Seropédica", no qual estive presente. 
10. Mauro Britto foi vereador em Seropédica durante três mandatos consecutivos (2001/2012). Dos doze anos de vereança, atuou como presidente da Câmara Municipal de Seropédica durante dez. Foi sob sua presidência que aconteceram as modificações legislativas que vão viabilizar a vinda do aterro para Seropédica. Ele nos concedeu uma longa entrevista em 23/12/14 e é nossa principal fonte dentre aqueles "a favor do aterro".

11. "E a empresa na verdade já tinha comprado a área. A empresa já estava em uma relação com o Eduardo Paes. Uma relação íntima. Mas a empresa comprou uma fazenda. Aquilo para eles e nada é a mesma coisa. Estão acostumados a fazer isso. Eles que estão fazendo Belo Monte." (BRITTO, entrevista).

12. "Claro que a gente sabe que a presidente não vai aparecer numa história dessa, mas a gente sabia que estava por trás de tudo isso." (BRITTO, entrevista).

13. Trechos retirados das entrevistas estruturadas que fiz no centro de Seropédica em julho de 2011.

14. Conforme Convenção da Basiléia e a própria PNRS.

15. Conforme Resolução Comitê Guandu no38 de 28 de setembro de 2009.

16. O EIA/RIMA é o documento elaborado por técnicos que preveem os impactos positivos e negativos de um empreendimento, a fim de subsidiar o órgão ambiental competente em suas análises.

17. Arquiteta e Urbanista, defendeu tese de doutorado em 25 de junho de 2020 no PROURB/UFRJ, intitulada "Aterro Sanitário de Seropédica (RJ): reflexos sociais e urbanos", e me cedeu, gentilmente, seus slides para esse artigo.

18. São as ETRs de Jacarepaguá, Marechal Hermes, Caju, Santa Cruz e Bangu. ETR Penha e Taquara não se encontram ainda em operação

\section{RESUMOS}

$\mathrm{O}$ artigo tem como objetivo contar um pouco da história da implementação do aterro sanitário de Seropédica (CTR Rio) para receber todo o lixo do município do Rio de Janeiro, dentre outros municípios, ressaltando a frágil relação intermetrópole, em que a cidade central reforça o papel de zona de sacrifício da cidade periférica e, ainda, os reais impactos socioambientais, positivos e negativos, do funcionamento da unidade. Para tal, traz alguns referenciais teóricos, destacando o processo de metropolização em curso que, à luz da teoria da Justiça Ambiental, demonstra a nova função que Seropédica passa a desenvolver na dinâmica metropolitana.

The article aims to tell a short history about the Seropédica landfill (CTR Rio) installation to receive all the waste from the municipality of Rio de Janeiro, among other municipalities, underscoring the fragile inter-metropolis relationship, on what the central city reinforces the role of the peripheral city as a sacrifice zone, and also the real, positive and negative, socioenvironmental impacts of the unit's operation. It brings some theoretical references, highlighting the ongoing metropolization process that, in the light of the Environmental Justice theory, demonstrates the new function that Seropédica develops in the metropolitan dynamics. 
L'article vise à raconter un peu l'histoire de la mise en place de la décharge de Seropédica (CTR Rio) pour recevoir toutes les ordures de la municipalité de Rio de Janeiro, entre autres municipalité, en mettant en évidence la fragile relation intermétropole, dans laquelle la ville centrale renforce le rôle de la zone de sacrifice de la ville périphérique et, aussi, les impacts socio-environnementaux réels, positifs et négatifs, du fonctionnement de l'unité. À cette fin, il apporte quelques références théoriques, mettant en évidence le processus de métropolisation en cours qui, à la lumière de la théorie de la Justice Environnementale, démontre la nouvelle fonction que Seropédica commence à développer dans la dynamique métropolitaine.

El articulo tiene el objetivo narrar la historia da implantación del relleno sanitario de Seropédica (CTR Rio) para recibir la toda la basura del municipio de Rio de Janeiro y de otros municipios, destacando la frágil relación intra metropolitana, en que la ciudad central refuerza el papel de la ciudad periférica como zona de sacrificio $\mathrm{y}$, también, los reales impactos socioambientales, positivos y negativos, de la operación de la unidad fabril. Para esto, traemos algunas referencias teóricas, destacando el proceso de metropolización en curso que, a la luz de la teoría de la justicia ambiental, apunta la nueva función que Seropédica pasa a desarrollar en la dinámica metropolitana.

\section{ÍNDICE}

Mots-clés: Décharge, Justice Environnementale, Seropédica, Metropolisation, Périphérie.

Palavras-chave: Aterro Sanitário, Justiça Ambiental, Seropédica, Metropolização, Periferia.

Palabras claves: Relleno Sanitario; justicia ambiental, Seropédica, Metropolización, Periferia.

Keywords: Landfill, Environmental Justice, Seropédica, Metropolization, Periphery.

\section{AUTOR}

\section{TATIANA COTTA G. PEREIRA}

Professora do Departamento de Ciências Jurídicas e do Programa de Pós Graduação em Desenvolvimento Territorial e Políticas Públicas da UFRRJ. Doutora em Sociologia e Direito. Email: tatianacotta75@gmail.com. 